\title{
Genetic Characterization of Didymella bryoniae Isolates Infecting Watermelon and Other Cucurbits in Florida and Georgia
}

Binoy Babu, North Florida Research and Education Center (NFREC), Institute of Food and Agricultural Sciences, University of Florida, Quincy 32351; Yonas W. Kefialew, NFREC, University of Florida and Ethiopian Institute of Agricultural Research, Gambella Agricultural Research Institute, Gambella, Ethiopia; Ping-Fang Li and Xing-Ping Yang, Institute of Vegetable Crops, Jiangsu Academy of Agricultural Sciences, Nanjing, China; Sheeja George and Eric Newberry, NFREC, University of Florida; Nicholas Dufault, Department of Plant Pathology, Institute of Food and Agricultural Sciences, University of Florida, Gainesville 32611; Dawit Abate, Department and Microbial, Cellular and Molecular Biology, Addis Ababa University, Addis Ababa, Ethiopia; Amare Ayalew, School of Plant Sciences, Haramaya University, Dire Dawa, Ethiopia; and Jim Marois and Mathews L. Paret, NFREC, University of Florida

\begin{abstract}
Babu, B., Kefialew, Y. W., Li, P.-F., Yang, X.-P., George, S., Newberry, E., Dufault, N., Abate, D., Ayalew, A., Marois, J., and Paret, M. L. 2015. Genetic characterization of Didymella bryoniae isolates infecting watermelon and other cucurbits in Florida and Georgia. Plant Dis. 99:1488-1499.

Gummy stem blight caused by Didymella bryoniae (anamorph Phoma cucurbitacearum) is a major fungal disease of watermelon (Citrullus lanatus) and other cucurbits. Thirty-five isolates of Didymella and Phoma spp. associated with symptoms of gummy stem blight on watermelon, Canary melon (Cucumis melo), muskmelon (C. melo), and winter squash (Cucurbita maxima) from Florida and Georgia were characterized based on morphology on agar media, pathogenicity on 'Melody' watermelon, the internal transcribed spacer (ITS) sequence of ribosomal DNA (rDNA), random amplified polymorphic DNA (RAPD) analysis, and polymerase chain reaction (PCR) restriction fragment length polymorphism (RFLP) analysis. All of the isolates

were pathogenic on watermelon but differed in virulence. RAPD and ITS sequence analysis indicated genetic variability among the isolates but PCR-RFLP analysis did not show any variability. ITS sequence phylogenetic analysis identified two isolates, DB-05 and DB-33, which had a greater identity to that of $D$. bryoniae isolates from China (98 to $100 \%$ sequence homology) than other isolates from Florida and Georgia (95 to 98\%). These two isolates possessed a single nucleotide substitution of A to $\mathrm{G}$ at position 131 of the ITS1 region. The study characterized the genetic profile of a collection of $D$. bryoniae isolates from Florida and Georgia in relation to isolates from other U.S. states and countries.
\end{abstract}

Didymella bryoniae (Fuckel) Rehm (anamorph Phoma cucurbitacearum (Fr.) Sacc.), synonym Stagonosporopsis cucurbitacearum (Fr.) Aveskamp, Gruyter \& Verkley (Aveskamp et al. 2010), is an ascomycete that causes gummy stem blight, a destructive foliar disease of cucurbits (Somai et al. 2002a). Gummy stem blight has been reported throughout the world but the disease is most devastating in warm and humid climates (Bala and Hosein 1986; McGrath et al. 1993; Punithalingam and Holliday 1972; Sitterly and Keinath 1996). D. bryoniae infects a wide range of plants in the family Cucurbitaceae, including watermelon (Citrullus lanatus (Thunb.) Matsum. \& Nakai), muskmelon (Cucumis melo L.), cucumber (Cucumis sativus L.), squash (Cucurbita pepo), and pumpkin (Cucurbita spp.) (Norton and Cosper 1989; Norton et al. 1986; Sitterly and Keinath 1996; St. Amand and Wehner 1991). Among the cucurbits, watermelon typically is the most severely affected in the southeastern United States (Keinath and Duthie 1998; Sitterly and Keinath 1996).

Florida and Georgia are the two major states for production of watermelon in the United States, with a combined 20,234 ha and \$219 million farm gate value in 2012 (United States Department of Agriculture National Agricultural Statistics Service 2013). This represents 39.5\% of the area of watermelon production and $42.1 \%$ of the total watermelon farm gate value for the United States, respectively. A total 146,059 kg of watermelon seed was imported into the United States in 2011, of which $79 \%$ originated from Chile, China, Egypt, Israel, Peru, and Thailand (United States Department of Agriculture 2013a). The significant global trade of seed presents a risk of introducing exotic strains of $D$. bryoniae

Corresponding author: M. L. Paret; E-mail: paret@ufl.edu

*The $\boldsymbol{e}$-Xtra logo stands for "electronic extra" and indicates that 1 supplementary table is included in the online edition.

Accepted for publication 13 March 2015.

http://dx.doi.org/10.1094/PDIS-04-14-0341-RE

(C) 2015 The American Phytopathological Society on seed imported into the United States because of the seedborne nature of the pathogen (Brown et al. 1970; Lee et al. 1984).

The first step in understanding the potential for movement of D. bryoniae into the United States on imported seed is to understand the current genetic profile of $D$. bryoniae isolates present in the United States. Molecular techniques such as polymerase chain reaction (PCR) assays, amplified fragment length polymorphism (AFLP) analysis, and random amplified polymorphic DNA (RAPD) analysis have been well utilized for characterization of $D$. bryoniae (Keinath et al. 1995; Kothera et al. 2003; Somai et al. 2002a,b). RAPD assays along with PCR amplification and sequencing of the internal transcribed spacer (ITS) region of ribosomal DNA (rDNA) have facilitated genetic fingerprinting of isolates from specific geographical locations (Somai et al. 2002a).

Previous studies using RAPD analysis differentiated $D$. bryoniae isolates into three genotypes: RG-I, RG-II, and RG-IV (Keinath et al. 1995; Somai et al. 2002a). Other Phoma spp. clustered into a separate group, RG-III (Keinath et al. 1995; Somai et al. 2002a,b; Zuniga 1999). Sequence-characterized amplified region (SCAR) markers based on RAPD profiles have been used for the development of specific PCR primers for differentiation of the three D. bryoniae groups and the Phoma group (Keinath et al. 2001; Somai et al. 2002b). RG-I was the most predominant group in the United States (Keinath et al. 2001; Kothera et al. 2003). Isolates from the RG-I group were more virulent on watermelon than isolates from the other groups (Santos et al. 2009; Somai et al. 2002a). Nucleotide sequence analysis of the ITS1 and ITS2 regions of rDNA (Schoch et al. 2012) also clustered D. bryoniae isolates from selected geographic locations in the United States into four RG groups (Somai et al. 2002a). The analyses placed the RG-I and RG-II groups into a common phylogenetic cluster along with the closely related isolates of RG-IV, while the Phoma spp. in RG-III clustered separately. Kothera et al. (2003) reported the presence of several clusters within the RG-I and RG-II groups, as well as among isolates from the northern and southern United States using AFLP analysis.

Most of these studies on the genetic characterization of $D$. bryoniae isolates have been carried out primarily with isolates from New York, Wisconsin, and South Carolina (Keinath et al. 1995; Somai et al 
2002a). The studies included two Florida isolates, one each from watermelon and muskmelon. Another genetic characterization study included six Florida and three Georgia isolates using AFLP analysis (Kothera et al. 2003). Studies focused on D. bryoniae isolates from Florida and Georgia have not taken place despite the importance of Florida and Georgia as the major watermelon-producing states in the United States. Therefore, the objectives of this study were to (1) characterize D. bryoniae isolates collected from watermelon and other cucurbit hosts from Florida and Georgia and (2) compare the genetic profile of Florida and Georgia isolates with that of $D$. bryoniae isolates from other geographic locations, to test the hypothesis that $D$. bryoniae isolates present in Florida and Georgia may possess unique genetic profiles compared with isolates from other locations in the United States as well as isolates from other countries from which watermelon seed is imported into the United States.

\section{Materials and Methods}

Isolate collection. Watermelon and other cucurbits showing typical symptoms of gummy stem blight were obtained from infected stem or leaf tissues in 2011 to 2012 from several locations in Florida and Georgia (Table 1). A section $\left(1 \mathrm{~cm}^{2}\right)$ of infected tissue from each symptomatic plant was surface sterilized in $0.6 \%$ sodium hypochlorite for $30 \mathrm{~s}$. The tissue was then rinsed twice in sterilized deionized water, and placed onto quarter-strength potato dextrose agar (QPDA). The plates were then incubated at $24^{\circ} \mathrm{C}$ with a 12 -h photoperiod/day for 10 to 14 days under white fluorescent light (Keinath et al. 1995; Somai et al. 2002a). The pure culture of each of the 30 watermelon isolates, 3 Canary melon isolates, and 1 isolate each from muskmelon and squash were further characterized as a Didymella sp. or a Phoma sp. based on colony morphology and spore characteristics, as described below (Keinath et al. 1995).

Morphological characterization. The morphological and cultural characteristics of the D. bryoniae and Phoma isolates were evaluated using four agar media. Each isolate was grown on QPDA, malt extract agar (MEA), malt extract yeast extract agar (MEYEA), and V8 juice agar (V8) (Atlas 2010). A 5-mm-diameter agar plug of a 3-day-old culture of each isolate on PDA was placed onto

Table 1. Origin, pathogenicity, and molecular characterization of Didymella bryoniae and Phoma spp. isolates from Florida and Georgia

\begin{tabular}{|c|c|c|c|c|c|c|c|c|c|c|}
\hline \multirow[b]{3}{*}{ Accession $^{\mathbf{a}}$} & \multirow[b]{3}{*}{ Isolate } & \multirow{2}{*}{\multicolumn{2}{|c|}{ Origin }} & \multirow[b]{3}{*}{ County ${ }^{c}$} & \multirow[b]{3}{*}{ Virulence $^{\mathrm{d}}$} & \multicolumn{5}{|c|}{ Molecular characterization } \\
\hline & & & & & & \multirow{2}{*}{$\begin{array}{l}\text { RG-I-F/ } \\
\text { RG-I-F }^{\mathrm{e}}\end{array}$} & \multirow{2}{*}{$\begin{array}{l}\text { RG-II-F/ } \\
\text { RG-II-R }^{\text {e }}\end{array}$} & \multirow{2}{*}{$\begin{array}{l}\text { RG-III-R/ } \\
\text { RG-III-F }\end{array}$} & \multirow[b]{2}{*}{ ITS-1/ITS-4 ${ }^{\mathrm{f}}$} & \multirow[b]{2}{*}{ Molecular identity } \\
\hline & & Host $^{\mathbf{b}}$ & Geographic & & & & & & & \\
\hline KF990378 & DB-01 & WM & Georgia & NA & $* * * *(7)$ & + & - & - & Clade 1a & $\begin{array}{l}\text { Stagonosporopsis } \\
\text { cucurbitacearum }\end{array}$ \\
\hline KF990379 & DB-02 & WM & Georgia & NA & $*(2)$ & + & - & - & Clade 1a & S. cucurbitacearum \\
\hline KF990380 & DB-04 & WM & Georgia & NA & $* *(5)$ & + & - & - & Clade 1a & S. cucurbitacearum \\
\hline KF990381 & DB-05 & WM & Georgia & NA & $* * * *(8)$ & + & - & - & Clade 2 & S. cucurbitacearum \\
\hline KF990382 & DB-06 & WM & Georgia & NA & $* * *(6)$ & - & - & - & Clade 1a & S. cucurbitacearum \\
\hline KF990383 & DB-07 & WM & Georgia & NA & $* * *(6)$ & + & - & - & Clade 1a & S. cucurbitacearum \\
\hline KF990384 & DB-08 & WM & Georgia & NA & $* * * *(11)$ & + & - & - & Clade 1a & S. cucurbitacearum \\
\hline KF990385 & DB-09 & WM & Florida & Santa Rosa & $*(2)$ & - & - & - & Clade $1 \mathrm{~b}$ & S. cucurbitacearum \\
\hline KF990386 & DB-10 & WM & Florida & Santa Rosa & $* * * *(11)$ & + & - & - & Clade 1a & S. cucurbitacearum \\
\hline KF990387 & DB-11 & WM & Florida & Santa Rosa & $* *(5)$ & + & - & - & Clade 1a & S. cucurbitacearum \\
\hline KF990388 & DB-12 & WM & Florida & Santa Rosa & $* * * *(11)$ & + & - & - & Clade 1a & S. cucurbitacearum \\
\hline KF990389 & DB-13 & WM & Florida & Santa Rosa & $* * *(6)$ & + & - & - & Clade $1 \mathrm{~b}$ & S. cucurbitacearum \\
\hline KF990390 & DB-15 & $\mathrm{CM}$ & Florida & Santa Rosa & $* * *(6)$ & + & - & - & Clade 1a & S. cucurbitacearum \\
\hline KF990391 & DB-18 & $\mathrm{CM}$ & Florida & Santa Rosa & $* * *(6)$ & + & - & - & Clade 1a & S. cucurbitacearum \\
\hline KF990392 & DB-19 & $\mathrm{CM}$ & Florida & Santa Rosa & $*(4)$ & + & - & - & Clade 1a & S. cucurbitacearum \\
\hline KF990393 & DB-20 & WM & Florida & Santa Rosa & $* * *(6)$ & + & - & - & Clade $1 \mathrm{~b}$ & S. cucurbitacearum \\
\hline KF990394 & DB-21 & WM & Florida & Santa Rosa & $* * * *(11)$ & + & - & - & Clade $1 \mathrm{~b}$ & S. cucurbitacearum \\
\hline KF990395 & DB-23 & WM & Florida & Santa Rosa & $* * *(6)$ & + & - & - & Clade $1 \mathrm{~b}$ & S. cucurbitacearum \\
\hline KF990396 & DB-24 & WM & Florida & Santa Rosa & $* * * *(11)$ & + & - & - & Clade $1 \mathrm{~b}$ & S. cucurbitacearum \\
\hline KF990397 & DB-25 & WM & Florida & Santa Rosa & $* * *(6)$ & + & - & - & Clade 1a & S. cucurbitacearum \\
\hline KF990409 & DB-27 & WM & Florida & Santa Rosa & $* * *(6)$ & - & - & + & Clade 3 & Phoma spp. \\
\hline KF990398 & DB-30 & WM & Florida & Jackson & $* * * *(11)$ & + & - & - & Clade 1a & S. cucurbitacearum \\
\hline KF990399 & DB-32 & WM & Florida & Gadsden & $* *(5)$ & + & - & - & Clade 1a & S. cucurbitacearum \\
\hline KF990400 & DB-33 & WM & Florida & Gadsden & $*(3)$ & - & - & - & Clade 2 & S. cucurbitacearum \\
\hline KF990401 & DB-34 & WM & Florida & Gadsden & $* * * *(11)$ & + & - & - & Clade 1a & S. cucurbitacearum \\
\hline KF990411 & DB-35 & WM & Florida & Gadsden & $*(4)$ & - & - & - & Clade 3 & Phoma spp. \\
\hline KF990402 & DB-36 & WM & Florida & Gadsden & $*(2)$ & - & - & - & Clade $1 \mathrm{~b}$ & S. cucurbitacearum \\
\hline KF990403 & DB-37 & WM & Florida & Alachua & $* * * *(11)$ & + & - & - & Clade 1a & S. cucurbitacearum \\
\hline KF990404 & DB-38 & MM & Florida & Alachua & $* * * *(11)$ & + & - & - & Clade 1a & S. cucurbitacearum \\
\hline KF990405 & DB-39 & WM & Florida & Levy Co. & $* * * *(11)$ & + & - & - & Clade 1a & S. cucurbitacearum \\
\hline KF990406 & DB-40 & WM & Florida & Alachua & $* *(5)$ & - & - & - & Clade $1 \mathrm{~b}$ & S. cucurbitacearum \\
\hline KF990407 & DB-42 & WM & Florida & Marion & $* * * *(11)$ & + & - & - & Clade 1a & S. cucurbitacearum \\
\hline KF990410 & DB-43 & WM & Florida & Marion & $* * * *(7)$ & - & - & - & Clade 3 & Phoma spp. \\
\hline KF990408 & DB-44 & SQ & Florida & Putnam & $*(4)$ & - & - & - & Clade $1 \mathrm{~b}$ & S. cucurbitacearum \\
\hline KF990412 & DB-45 & WM & Florida & Putnam & $* *(5)$ & - & - & - & Clade 3 & Phoma spp. \\
\hline
\end{tabular}

a Accession number of isolates deposited in the GenBank National Center for Biotechnology Information database.

${ }^{\mathrm{b}} \mathrm{WM}=$ watermelon (Citrullus lanatus), $\mathrm{CM}=$ Canary melon (Cucumis melo), $\mathrm{MM}=$ muskmelon (C. melo), and SQ = squash (Cucurbita maxima).

${ }^{\mathrm{c}} \mathrm{NA}=$ Information on the county is not available.

d Virulence rating: $*=\operatorname{low}(1$ to $25 \%), * *=$ medium $(25$ to $50 \%)$, $* * *=$ severe $(50$ to $75 \%)$, and $* * * *=$ extreme $(75$ to $100 \%)$. Disease severity $=$ average of the Horsfall-Barratt rating done 30 days after inoculation, indicated in parentheses.

e Random amplified polymorphic DNA generated sequence-characterized amplified region (RG-SCAR)-based primers (Keinath et al. 2001; Somai et al. 2002b) used for the differentiation of Didymella bryoniae and Phoma spp. isolates into specific RG groups.

${ }^{\mathrm{f}}$ Internal transcribed spacer (ITS) ribosomal DNA (rDNA) region-based primers ITS1 and ITS4 (White et al. 1990) used for the genetic characterization of D. bryoniae and Phoma spp. isolates. Phylogenetic cluster was based on a 545-bp sequence of the ITS rDNA region.

$\mathrm{g}$ Identity based on a 545-bp nucleotide sequence of the ITS rDNA region obtained using ITS1 and ITS4 primers. 
a 9-mm-diameter petri plate containing the appropriate agar medium. Each isolate was grown on three replicate plates of each medium. Cultures were incubated at $25^{\circ} \mathrm{C}$ for 5 days in the dark and an additional 7 days with $12 \mathrm{~h}$ of light per day. Daily growth of the isolate on each plate was recorded as the average colony diameter, measured in two perpendicular directions each day for 12 days. Colony characteristics were also recorded based on color, elevation (flat or raised), margin, and conidia formation (Keinath et al. 1995). Slides were prepared to make detailed observations of the mycelium, conidia, pycnidia, and pseudothecia with a light microscope (Nikon Eclipse 80i; Nikon Instruments Inc., Melville, NY). Fungal structures were taken from colonies growing on PDA, mounted in lactophenol cotton blue, and examined microscopically. The length and width of each of 50 conidia and the presence of septa in the conidia from each isolate were measured at ×400 magnification.

Pathogenicity test. All isolates were subjected to a pathogenicity test as described by Keinath et al. (1995). 'Melody' watermelon seed (Syngenta Seeds Inc., Minnetonka, MN) were planted in a seedling tray consisting of 128 cells with individual cells of 3.5 by 3.5 by $4.5 \mathrm{~cm}$ (length by width by height) containing Metro Mix planting medium (Sun Gro Horticulture, Agawam, MA). The greenhouse was set at $28 \pm 4^{\circ} \mathrm{C}$ and relative humidity was maintained at 75 to $85 \%$. At the four-leaf stage, seedlings were transplanted to 10 -cm-diameter plastic pots with one seedling/pot. D. bryoniae and Phoma sp. isolates grown at $24^{\circ} \mathrm{C}$ for 10 to 14 days on MEA under a photoperiod of $12 \mathrm{~h} /$ day in 80-mm-diameter petri plates were used for inoculation. Sterilized, deionized water $(20 \mathrm{ml})$ containing $0.05 \%$ Tween 20 was added to each plate, and the surface of the medium was scraped gently with a sterilized loop to release the conidia. The resulting conidial suspension was filtered through four layers of sterilized cheesecloth to remove mycelial fragments. The conidial suspension was then diluted with sterilized, deionized water and adjusted to a final concentration of $10^{5}$ conidia/ml using a hemocytometer. Plants were inoculated by spraying the suspension until run-off. Diseased leaf tissue from each plant was collected 30 days after inoculation, and the pathogen was reisolated and identified as described above to confirm Koch's postulates. The treatments for each pathogenicity test were arranged as a completely randomized design with three replicate pots for each isolate. The test included three control plants sprayed with sterilized, deionized water. The experiment was repeated for confirmation. Plants were examined every other day for disease symptoms beginning the second day after inoculation. Gummy stem blight severity was assessed visually and rated from 0 to 11 using the Horsfall-Barratt scale (Horsfall and Barratt 1945). Severity ratings for the last assessment (30 days after inoculation) were converted to midpoint averages of disease severity. Virulence of each isolate was categorized based on the final percentage of foliage with symptoms as $*=$ low ( 1 to $25 \%$ ), $* *=$ medium $(25$ to $50 \%), * * *=$ severe $(50$ to $75 \%)$, and $* * * *=$ extreme (75 to $100 \%)$.

Table 2. Details of primers used for genetic characterization of Didymella bryoniae and Phoma spp. isolates from Florida and Georgia

\begin{tabular}{|c|c|}
\hline Primers & Sequence $\left(5^{\prime}-3^{\prime}\right)$ \\
\hline \multicolumn{2}{|l|}{ RG-SCAR ${ }^{\mathrm{a}}$} \\
\hline RG I-F & 5'-TGTCGTTGACATCATTCCAGC-3' \\
\hline RG-I-R & 5'-ACCACTCTGCTTAGTATCTGC-3' \\
\hline RG-II-F & 5'-GCTAAGCCTTAATCTAGCTGC-3' \\
\hline RG-II-R & 5'-GAGAGTAAGCTAACCTAAAGG-3' \\
\hline RG-III-F & 5'-GTCAGAGTTCAGAATGCTTCG-3' \\
\hline RG-III-R & $5^{\prime}$ - ACGGATGAATAACACGGAAGA-3' \\
\hline \multicolumn{2}{|l|}{ ITS $^{\mathrm{b}}$} \\
\hline ITS1 & $5^{\prime}$-TCC GTA GGT GAA CCT GCG G-3' \\
\hline ITS4 & $5^{\prime}$-TCC TCC GCT TAT TGA TAT GC- $3^{\prime}$ \\
\hline \multicolumn{2}{|c|}{$\begin{array}{l}\text { a Random amplified polymorphic DNA generated sequence-characterized } \\
\text { amplified region (RG-SCAR) primers used for the differentiation of Didy- } \\
\text { mella bryoniae and Phoma spp. (Keinath et al. 2001; Somai et al. 2002b). } \\
\text { b Primers used for the amplification of the internal transcribed spacer (ITS) } \\
\text { ribosomal DNA region of the D. bryoniae and Phoma spp. (White et al. } \\
\text { 1990) isolates. }\end{array}$} \\
\hline
\end{tabular}

Genomic DNA extraction. Each purified isolate was grown on QPDA and incubated at $28^{\circ} \mathrm{C}$ with a photoperiod of $12 \mathrm{~h}$ /day for 10 to 14 days. Mycelium (100 to $120 \mathrm{mg}$ ) was scraped from the culture plate under aseptic conditions and homogenized using liquid nitrogen in a mortar with a pestle. The tissue was ground to a fine powder and the genomic DNA was extracted using the Plant/Fungi DNA Isolation Kit (NorgenBiotek, Ontario, Canada). The DNA was eluted in sterilized, nuclease-free water and stored at $-20^{\circ} \mathrm{C}$. The DNA was then quantified in a $1 \%$ agarose gel stained with ethidium bromide.

Genetic diversity analysis of isolates based on RG-specific SCAR primers. The isolates were each subjected to a PCR assay using the RG-specific primers (Table 2) (Keinath et al. 2001; Somai et al. 2002b). The PCR reactions were performed in a $20-\mu l$ volume containing $40 \mathrm{ng}$ of DNA, $2.0 \mu \mathrm{l}$ of $10 \times$ reaction buffer $(50 \mathrm{mM}$ Tris- $\mathrm{HCl}, 1.5 \mathrm{mM} \mathrm{MgCl} 2,15 \mathrm{mM}\left(\mathrm{NH}_{4}\right)_{2} \mathrm{SO}_{4}$, and $0.1 \%$ Triton $\mathrm{X}-100), 200 \mu \mathrm{M}$ dNTPs, $2.5 \mathrm{U}$ of Taq DNA polymerase $(5 \mathrm{U} / \mu \mathrm{l})$, and $0.25 \mu \mathrm{M}$ each primer. The PCR assay was performed in an Eppendorf Mastercycler gradient ES, with the annealing temperature decreased from 64 (Somai et al. 2002b) to $62^{\circ} \mathrm{C}$. The thermal cycling program was as follows: $94^{\circ} \mathrm{C}$ for $2 \mathrm{~min} ; 35$ cycles of $94^{\circ} \mathrm{C}$ for $1 \mathrm{~min}$, $62^{\circ} \mathrm{C}$ for $1 \mathrm{~min}$, and $72^{\circ} \mathrm{C}$ for $2 \mathrm{~min}$; followed by $72^{\circ} \mathrm{C}$ for $10 \mathrm{~min}$. The amplified product was analyzed on a $1 \%$ agarose gel, stained with ethidium bromide, and photographed with a UV-gel documentation system (Alpha Imager; ProteinSimple, Santa Clara, CA).

PCR amplification of the isolates using ITS1 and ITS4 primers. The genomic DNA of each isolate was subjected to PCR amplification using universal primers (Table 2) (White et al. 1990). The PCR reaction was performed in a $20-\mu \mathrm{l}$ volume containing $40 \mathrm{ng}$ of DNA, $2.0 \mu \mathrm{l}$ of $10 \times$ reaction buffer $(50 \mathrm{mM}$ Tris- $\mathrm{HCl}, 1.5 \mathrm{mM} \mathrm{MgCl}$, $15 \mathrm{mM}\left(\mathrm{NH}_{4}\right)_{2} \mathrm{SO}_{4}$, and $0.1 \%$ Triton $\left.\mathrm{X}-100\right), 200 \mu \mathrm{M}$ dNTPs, $2.5 \mathrm{U}$ of Taq DNA polymerase ( $5 \mathrm{U} / \mu \mathrm{l})$, and $0.25 \mu \mathrm{M}$ each primer. The PCR assay was performed in an Eppendorf Mastercycler gradient ES with the following cycling conditions: $95^{\circ} \mathrm{C}$ for $4 \mathrm{~min} ; 35$ cycles of $95^{\circ} \mathrm{C}$ for $1 \mathrm{~min}, 62^{\circ} \mathrm{C}$ for $1 \mathrm{~min}$, and $72^{\circ} \mathrm{C}$ for $2 \mathrm{~min}$; followed by $72^{\circ} \mathrm{C}$ for $8 \mathrm{~min}$. The amplified product was analyzed on a $1 \%$ agarose gel, stained with ethidium bromide, and photographed with a UV-gel documentation system (Alpha Imager).

Sequencing of the ITS rDNA and phylogenetic analysis. The PCR products were purified using the Qiagen Minielute PCR purification kit (Qiagen, Valencia, CA) and then subjected to sequencing using an Applied Biosystems 3730 Genetic Analyzer. The sequencing was performed bidirectionally using the specific primers. The sequences were subjected to end-to-end alignment and edited using BIOEDIT (Hall 1999). The nucleotide sequences were compared with those in the National Center for Biotechnology Information (NCBI) database using the Basic Local Alignment Search Tool (BLAST; http://www.ncbi.nlm.nih.gov/blast/), with Blastn. Sequences of the accessions that had the greatest ( $>85 \%$ ) sequence identity were considered for further phylogenetic analysis. Multiple sequence alignment for the isolates and the percent homology between aligned sequences were calculated using Clustal W (Thompson et al. 1994). A sequence identity matrix was constructed using BIOEDIT. From the aligned sequences, a phylogenetic tree was constructed using the neighbor-joining method (Tajima and Nei 1984), with the data sets subjected to 1,000 bootstrap replicates using $S$. heliopsidis as the outgroup (Aveskamp et al. 2010) (M. Brewer, University of Georgia, unpublished data). Tree was constructed using MEGA 5.2 (Tamura et al. 2011). The phylogenetic analysis was performed for sequences of the 35 D. bryoniae isolates from Florida and Georgia alone as well as in combination with 59 sequences of $D$. bryoniae isolates from the NCBI database (Table 3).

PCR-RFLP analysis of ITS rDNA. The PCR assay amplified a 545-bp ITS region of the rDNA of each isolate, which was then subjected to restriction analysis using the enzymes MspI and TaqI (New England Biolabs, Ontario, Canada) as per the manufacturer's instructions. The restricted fragments were separated on a $2 \%$ agarose gel, stained with ethidium bromide, and photographed with a UV-gel documentation system.

Genetic diversity analysis using RAPD assay. The genetic diversity of the 35 D. bryoniae isolates was analyzed using RAPD genetic 
Table 3. Details of Didymella bryoniae isolates from the GenBank National Center for Biotechnology Information (NCBI) database for phylogenetic analysis of internal transcribed spacer ribosomal DNA region of Didymella bryoniae and Phoma spp. isolates from Florida and Georgia

\begin{tabular}{|c|c|c|c|}
\hline Accession $^{\mathbf{a}}$ & Isolate $^{b}$ & Host & Country of origin \\
\hline AF297228 & D. bryoniae & Muskmelon (Cucumis melo) & United States \\
\hline EF160073 & D. bryoniae TMK-1 & Muskmelon & China \\
\hline EF160074 & D. bryoniae TMK-2 & Muskmelon & China \\
\hline EF160075 & D. bryoniae TMK-3 & Muskmelon & China \\
\hline EF160076 & D. bryoniae TMK-4 & Muskmelon & China \\
\hline HQ914649 & Stagonosporopsis cucurbitacearum-ZE & Muskmelon & China \\
\hline JN886705 & S. cucurbitacearum-Scg1 & Watermelon (Citrullus lanatus) & Mexico \\
\hline EF107641 & D. bryoniae-Di-3 (425) & Watermelon & Taiwan \\
\hline EF107642 & D. bryoniae-Di-4 (426) & Watermelon & Tunisia \\
\hline GU045303 & S. cucurbitacearum $\mathrm{R}-\mathrm{J} 10$ & Watermelon & United States \\
\hline GU045304 & S. cucurbitacearum-R-T2 & Butternut squash (Cucurbita moschata) & United States \\
\hline AY293804 & S. cucurbitacearum-287ITS & Cucurbits $^{\mathrm{c}}$ & United States \\
\hline HQ684029 & S. cucurbitacearum-SP6 & Styrian oil pumpkin (Cucurbita pepo var. styriac) & Austria \\
\hline HQ684031 & S. cucurbitacearum-SP12 & Styrian oil pumpkin & Austria \\
\hline KF206169 & S. cucurbitacearum & Watermelon & China \\
\hline AB714984 & S. cucurbitacearum & Chayote (Sechium edule) & Taiwan \\
\hline AB714985 & S. cucurbitacearum-SE6 & Chayote & Taiwan \\
\hline AB714986 & S. cucurbitacearum-SE7 & Chayote & Taiwan \\
\hline DBJXJJ1 & D. bryoniae & Watermelon & China \\
\hline DBJXJJ2 & D. bryoniae & Watermelon & China \\
\hline DBJSXZ3 & D. bryoniae & Muskmelon & China \\
\hline DBJSXZ4 & D. bryoniae & Muskmelon & China \\
\hline DBJSXZ1 & D. bryoniae & Muskmelon & China \\
\hline DBJSXZ2 & D. bryoniae & Muskmelon & China \\
\hline DBZJNB1 & D. bryoniae & Watermelon & China \\
\hline DBZJNB2 & D. bryoniae & Watermelon & China \\
\hline DBZJNB3 & D. bryoniae & Watermelon & China \\
\hline DBZJNB4 & D. bryoniae & Watermelon & China \\
\hline DBZJNB5 & D. bryoniae & Watermelon & China \\
\hline DBZJNB6 & D. bryoniae & Watermelon & China \\
\hline DBZJNB7 & D. bryoniae & Muskmelon & China \\
\hline DBZJNB8 & D. bryoniae & Muskmelon & China \\
\hline DBZJNB9 & D. bryoniae & Muskmelon & China \\
\hline DBZJNB10 & D. bryoniae & Muskmelon & China \\
\hline DBZJNB11 & D. bryoniae & Muskmelon & China \\
\hline DBZJNB12 & D. bryoniae & Muskmelon & China \\
\hline DBJSJY1 & D. bryoniae & Muskmelon & China \\
\hline DBJSJY2 & D. bryoniae & Muskmelon & China \\
\hline DBJSJY3 & D. bryoniae & Muskmelon & China \\
\hline DBJSJY4 & D. bryoniae & Muskmelon & China \\
\hline DBJSJY5 & D. bryoniae & Muskmelon & China \\
\hline DBJSJY6 & D. bryoniae & Muskmelon & China \\
\hline DBJSJY7 & D. bryoniae & Muskmelon & China \\
\hline DBJSHM1 & D. bryoniae & Muskmelon & China \\
\hline DBJSHM2 & D. bryoniae & Muskmelon & China \\
\hline DBJSHM3 & D. bryoniae & Muskmelon & China \\
\hline DBJSDY1 & D. bryoniae & Muskmelon & China \\
\hline DBJSDY2 & D. bryoniae & Muskmelon & China \\
\hline DBJSDY3 & D. bryoniae & Muskmelon & China \\
\hline DBJSDY4 & D. bryoniae & Muskmelon & China \\
\hline DBJSLH1 & D. bryoniae & Muskmelon & China \\
\hline DBJSLH2 & D. bryoniae & Muskmelon & China \\
\hline DBJSLH3 & D. bryoniae & Muskmelon & China \\
\hline DBJSJAAS1 & D. bryoniae & Muskmelon & China \\
\hline DBJSJAAS2 & D. bryoniae & Muskmelon & China \\
\hline DBJSJAAS3 & D. bryoniae & Muskmelon & China \\
\hline DBJSJAAS4 & D. bryoniae & Muskmelon & China \\
\hline DBAHHF1 & D. bryoniae & Watermelon & China \\
\hline DBAHHF2 & D. bryoniae & Watermelon & China \\
\hline
\end{tabular}

${ }^{a}$ Accession number of $D$. bryoniae isolates from other geographic locations in the United States and other countries deposited in the GenBank NCBI database.

${ }^{\mathrm{b}}$ D. bryoniae isolates from NCBI database infecting various host plants, used in phylogenetic comparison of the internal transcribed spacer ribosomal DNA region of isolates from Florida and Georgia.

${ }^{\mathrm{c}}$ Information on the specific host is not available. 
fingerprinting. A set of RAPD 10-mer oligonucleotide primers (Operon Technologies, Alameda, CA) (OPA1-06, OPAA-04, OPAA-15, OPAA-17, OPK-01, OPK-04, OPK-08, OPL-03, OPL-05, OPL-15, OPL-19, OPN-09, OPT-07, OPT-13 and OPT-14) was initially screened with the 35 isolates. The assay was performed using the GoTaq Flexi DNA polymerase (Promega Corp., Madison, WI) in a $20-\mu 1$ reaction mixture containing $40 \mathrm{ng}$ of DNA, $4.0 \mu 1$ of $5 \times$ reaction buffer, $1.5 \mathrm{mM} \mathrm{MgCl} 2,200 \mu \mathrm{M}$ dNTPs, $2.5 \mathrm{U}$ of GoTaq Flexi

Table 4. Morphology of isolates of Didymella bryoniae and Phoma spp. from Florida and Georgia on quarter-strength potato dextrose agar medium

\begin{tabular}{|c|c|c|c|c|c|c|c|c|c|c|}
\hline \multirow[b]{2}{*}{ Isolate } & \multicolumn{2}{|c|}{ Colony color } & \multirow[b]{2}{*}{ Elevation $^{c}$} & \multirow{2}{*}{$\begin{array}{l}\text { Mycelium } \\
\text { color }\end{array}$} & \multirow{2}{*}{$\begin{array}{c}\text { Growth } \\
(\mathbf{m m})^{\mathbf{d}}\end{array}$} & \multirow[b]{2}{*}{ Pseud $^{\mathrm{e}}$} & \multirow[b]{2}{*}{ Pycne } & \multicolumn{3}{|c|}{$\begin{array}{l}\text { Conidial characteristics } \\
\text { (after } 12 \text { days) }\end{array}$} \\
\hline & Upper $^{\mathbf{a}}$ & Lower ${ }^{b}$ & & & & & & Septa $(\%)^{\mathrm{f}}$ & Length $(\mu \mathrm{m})^{\mathrm{g}}$ & Width $(\mu \mathrm{m})^{\mathrm{g}}$ \\
\hline \multicolumn{11}{|c|}{ Didymella bryoniae } \\
\hline DB-01 & Light gray & Olive & Flat & White & $6.3 \pm 0.12$ & $\mathrm{P}$ & $\mathrm{P}$ & 10 & $8.11 \pm 0.27$ & $2.95 \pm 0.06$ \\
\hline DB-02 & $\begin{array}{l}\text { Ghost white to } \\
\text { light gray }\end{array}$ & $\begin{array}{l}\text { Dark gray to } \\
\text { light olive }\end{array}$ & Flat & White & $4.3 \pm 0.35$ & $\mathrm{P}$ & $\mathrm{P}$ & 12 & $8.54 \pm 0.20$ & $3.95 \pm 0.31$ \\
\hline DB-04 & Light gray & Black & Flat & White & $4.3 \pm 0.81$ & $\mathrm{P}$ & $\mathrm{P}$ & 16 & $9.27 \pm 0.13$ & $3.83 \pm 0.23$ \\
\hline DB-05 & $\begin{array}{l}\text { Dark gray to } \\
\text { black }\end{array}$ & Black & Irregular & White & $5.0 \pm 0.27$ & $\mathrm{P}$ & $P$ & 20 & $7.58 \pm 0.23$ & $3.21 \pm 0.35$ \\
\hline DB-06 & $\begin{array}{l}\text { Medium gray } \\
\text { to white }\end{array}$ & Black & Flat & White & $4.7 \pm 0.41$ & A & A & $\cdots$ & $\cdots$ & $\ldots$ \\
\hline DB-07 & $\begin{array}{l}\text { Dark gray to } \\
\text { black }\end{array}$ & Black & Flat & White & $4.5 \pm 0.23$ & $\mathrm{P}$ & $P$ & 0 & $8.30 \pm 0.05$ & $3.11 \pm 0.35$ \\
\hline DB-10 & Light gray & $\begin{array}{l}\text { Dark gray to } \\
\text { black }\end{array}$ & Flat & Olive drab & $6.7 \pm 0.07$ & $\mathrm{P}$ & $\mathrm{P}$ & 40 & $9.45 \pm 0.13$ & $3.45 \pm 0.35$ \\
\hline DB-11 & $\begin{array}{l}\text { Light gray to } \\
\text { dark gray }\end{array}$ & $\begin{array}{l}\text { Black to } \\
\text { light gray }\end{array}$ & Flat & White & $5.7 \pm 0.07$ & $\mathrm{P}$ & $\mathrm{P}$ & 42 & $9.32 \pm 0.37$ & $4.16 \pm 0.23$ \\
\hline DB-13 & Light gray & Black & Flat & Olive & $8.0 \pm 0.24$ & $\mathrm{P}$ & $\mathrm{P}$ & 36 & $9.57 \pm 0.37$ & $4.83 \pm 0.31$ \\
\hline DB-18 & $\begin{array}{l}\text { Medium gray } \\
\text { to olive }\end{array}$ & Black & Flat & Olive & $5.2 \pm 0.37$ & $\mathrm{P}$ & $\mathrm{P}$ & 24 & $7.20 \pm 0.12$ & $2.77 \pm 0.23$ \\
\hline DB-20 & $\begin{array}{l}\text { Dark gray to } \\
\text { brown }\end{array}$ & Brown & Flat & Brown & $4.8 \pm 0.18$ & $\mathrm{P}$ & $\mathrm{P}$ & 16 & $9.30 \pm 0.50$ & $3.56 \pm 0.23$ \\
\hline DB-21 & Dark gray & Black & Flat & Olive & $8.3 \pm 0.07$ & $\mathrm{P}$ & $\mathrm{P}$ & 8 & $9.60 \pm 0.92$ & $4.19 \pm 0.12$ \\
\hline DB-23 & $\begin{array}{l}\text { Dark gray to } \\
\text { black }\end{array}$ & Black & Flat & White & $7.3 \pm 0.13$ & $P$ & $\mathrm{P}$ & 16 & $8.45 \pm 0.33$ & $3.44 \pm 0.23$ \\
\hline DB-24 & $\begin{array}{l}\text { Dark gray to } \\
\text { olive }\end{array}$ & Black & Flat & White & $9.7 \pm 0.35$ & $\mathrm{P}$ & $\mathrm{P}$ & 12 & $9.84 \pm 0.48$ & $3.73 \pm 0.35$ \\
\hline DB-25 & Medium gray & Black & Flat & Medium gray & $6.7 \pm 0.27$ & $\mathrm{P}$ & $\mathrm{P}$ & 0 & $9.24 \pm 0.27$ & $4.65 \pm 0.35$ \\
\hline DB-30 & Gray & Black & Flat & White & $6.8 \pm 0.35$ & $\mathrm{P}$ & $\mathrm{P}$ & 0 & $9.89 \pm 0.40$ & $4.77 \pm 0.31$ \\
\hline DB-33 & Medium gray & Medium gray & Flat & Silver & $20.2 \pm 0.55$ & A & A & $\ldots$ & $\ldots$ & $\ldots$ \\
\hline DB-34 & $\begin{array}{l}\text { Light brown to } \\
\text { gray }\end{array}$ & Black & Flat & Gray & $4.3 \pm 0.33$ & $\mathrm{P}$ & $\mathrm{P}$ & 18 & $8.67 \pm 0.12$ & $3.56 \pm 0.35$ \\
\hline DB-36 & $\begin{array}{l}\text { Dark gray to } \\
\text { white }\end{array}$ & Black & Flat & White & $5.7 \pm 0.33$ & A & A & $\ldots$ & $\ldots$ & $\ldots$ \\
\hline DB-37 & Gray to black & Gray to black & Flat & Black & $7.0 \pm 0.15$ & $\mathrm{P}$ & $\mathrm{P}$ & 8 & $9.90 \pm 0.48$ & $4.12 \pm 0.12$ \\
\hline DB-44 & Grayish white & Black & Flat & White & $9.9 \pm 0.23$ & A & A & $\ldots$ & $\ldots$ & $\ldots$ \\
\hline DB-19 & White & Black & Flat & White & $6.0 \pm 0.18$ & $\mathrm{P}$ & $\mathrm{P}$ & 18 & $8.90 \pm 0.35$ & $2.89 \pm 0.06$ \\
\hline DB-32 & White & White & Flat & White & $15.7 \pm 0.50$ & $\mathrm{P}$ & $\mathrm{P}$ & 0 & $7.75 \pm 0.18$ & $3.22 \pm 0.23$ \\
\hline DB-38 & White & Black & Flat & White & $3.5 \pm 0.12$ & $\mathrm{P}$ & $\mathrm{P}$ & 4 & $9.35 \pm 0.12$ & $3.46 \pm 0.35$ \\
\hline DB-39 & White & Black & Flat & White & $5.2 \pm 0.35$ & $\mathrm{P}$ & $\mathrm{P}$ & 0 & $7.20 \pm 0.53$ & $2.97 \pm 0.23$ \\
\hline DB-40 & White & Black & Flat & White & $5.3 \pm 0.00$ & A & $\mathrm{A}$ & $\ldots$ & $\ldots$ & $\ldots$ \\
\hline DB-42 & White & Black & Flat & White & $9.2 \pm 0.27$ & $\mathrm{P}$ & $\mathrm{P}$ & 0 & $9.45 \pm 0.23$ & $2.45 \pm 0.23$ \\
\hline DB-08 & Olive drab & Dark gray & Flat & White & $5.3 \pm 0.29$ & $\mathrm{P}$ & $\mathrm{P}$ & 24 & $8.60 \pm 0.13$ & $3.42 \pm 0.23$ \\
\hline DB-09 & $\begin{array}{l}\text { Light brown to } \\
\text { olive drab }\end{array}$ & $\begin{array}{l}\text { Dark gray to } \\
\text { black }\end{array}$ & Flat & Olive & $5.0 \pm 0.07$ & A & A & $\ldots$ & $\ldots$ & $\ldots$ \\
\hline DB-12 & Light olive drab & Black & Flat & White & $8.7 \pm 0.13$ & $\mathrm{P}$ & $\mathrm{P}$ & 0 & $8.51 \pm 0.12$ & $3.46 \pm 0.35$ \\
\hline DB-15 & $\begin{array}{l}\text { Dark brown to } \\
\text { olive }\end{array}$ & Black & Flat & White & $4.8 \pm 0.24$ & $\mathrm{P}$ & $\mathrm{P}$ & 38 & $7.94 \pm 0.27$ & $3.55 \pm 0.31$ \\
\hline \multicolumn{11}{|c|}{ Phoma spp. } \\
\hline DB-27 & Silver & Medium gray & Raised & Silver & $7.5 \pm 0.12$ & A & $\mathrm{P}$ & 0 & $6.99 \pm 0.18$ & $2.89 \pm 0.04$ \\
\hline DB-35 & $\begin{array}{l}\text { Light green to } \\
\text { silver }\end{array}$ & Black & Flat & White & $7.0 \pm 0.48$ & A & $\mathrm{P}$ & 0 & $7.11 \pm 0.00$ & $2.96 \pm 0.04$ \\
\hline DB-43 & $\begin{array}{l}\text { Light green to } \\
\text { silver }\end{array}$ & Brown & Flat & White & $6.0 \pm 0.41$ & A & $\mathrm{P}$ & 0 & $7.23 \pm 0.12$ & $3.01 \pm 0.23$ \\
\hline DB-45 & Brown to silver & Black & Flat & Brown & $5.4 \pm 0.24$ & A & $\mathrm{P}$ & 0 & $7.25 \pm 0.35$ & $2.89 \pm 0.12$ \\
\hline
\end{tabular}

${ }^{a}$ Morphological color of the D. bryoniae and Phoma spp. isolates from Florida and Georgia on the upper surface of the quarter-strength potato dextrose agar (QPDA) medium.

b Morphological color of the D. bryoniae and Phoma spp. isolates from Florida and Georgia on the lower surface of the QPDA medium.

c Morphological appearance (flat or raised) of the D. bryoniae and Phoma spp. isolates from Florida and Georgia on QPDA medium.

d Growth after 10 days.

e $\mathrm{P}=$ presence and $\mathrm{A}=$ absence of pseudothecia (Pseud) and pycnidia (Pycn).

${ }^{f}$ Percentage of conidia with septa.

g Mean \pm standard error for 50 conidia. 
DNA polymerase $(5 \mathrm{U} / \mu \mathrm{l})$, and $0.25 \mu \mathrm{M}$ each primer. The PCR assay was performed in an Eppendorf Mastercycler gradient ES with the following cycling conditions: $95^{\circ} \mathrm{C}$ for $2 \mathrm{~min} ; 35$ cycles of $95^{\circ} \mathrm{C}$ for $1 \mathrm{~min}, 35^{\circ} \mathrm{C}$ for $1 \mathrm{~min}$, and $72^{\circ} \mathrm{C}$ for $1 \mathrm{~min}$; followed by $72^{\circ} \mathrm{C}$ for $10 \mathrm{~min}$. The amplified product was analyzed on a $1 \%$ agarose gel, stained with ethidium bromide, and photographed with a UV-gel documentation system. The assay was repeated to assess consistency and reproducibility. Those primers that yielded clear, consistent, and polymorphic bands were selected for further analysis.

Data analysis. Computer-assisted evaluation of the RAPD-generated fingerprints were made using GelCompare II (version 6.6.8; Applied Math, Kortrijk, Belgium). For each primer, the RAPD markers that were

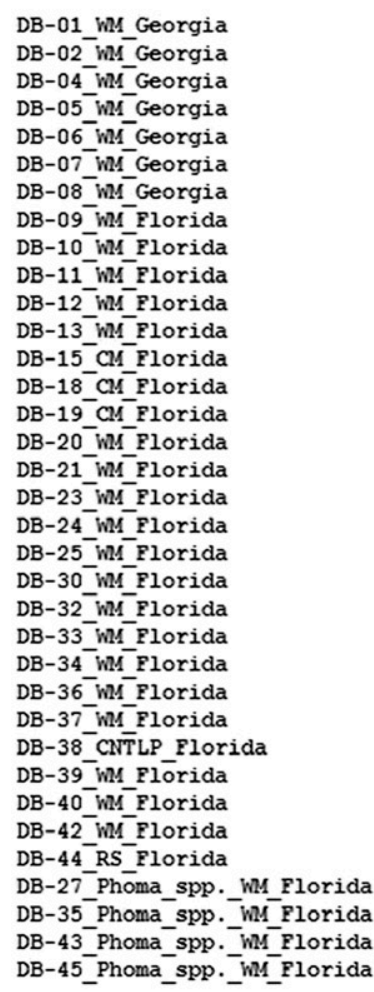

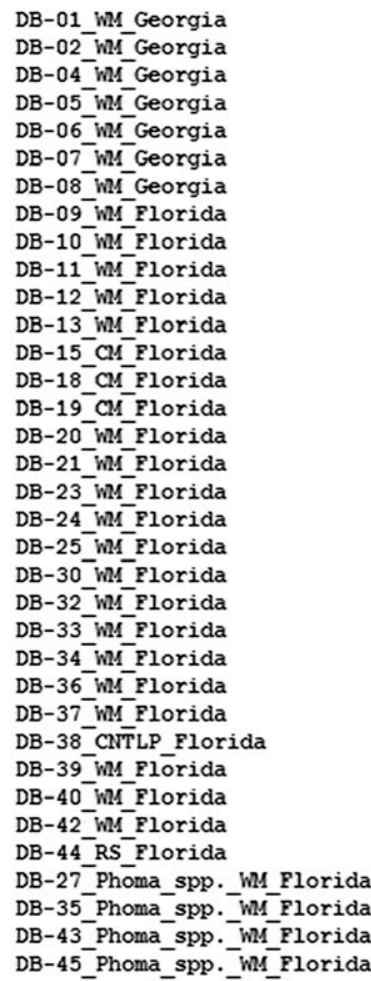
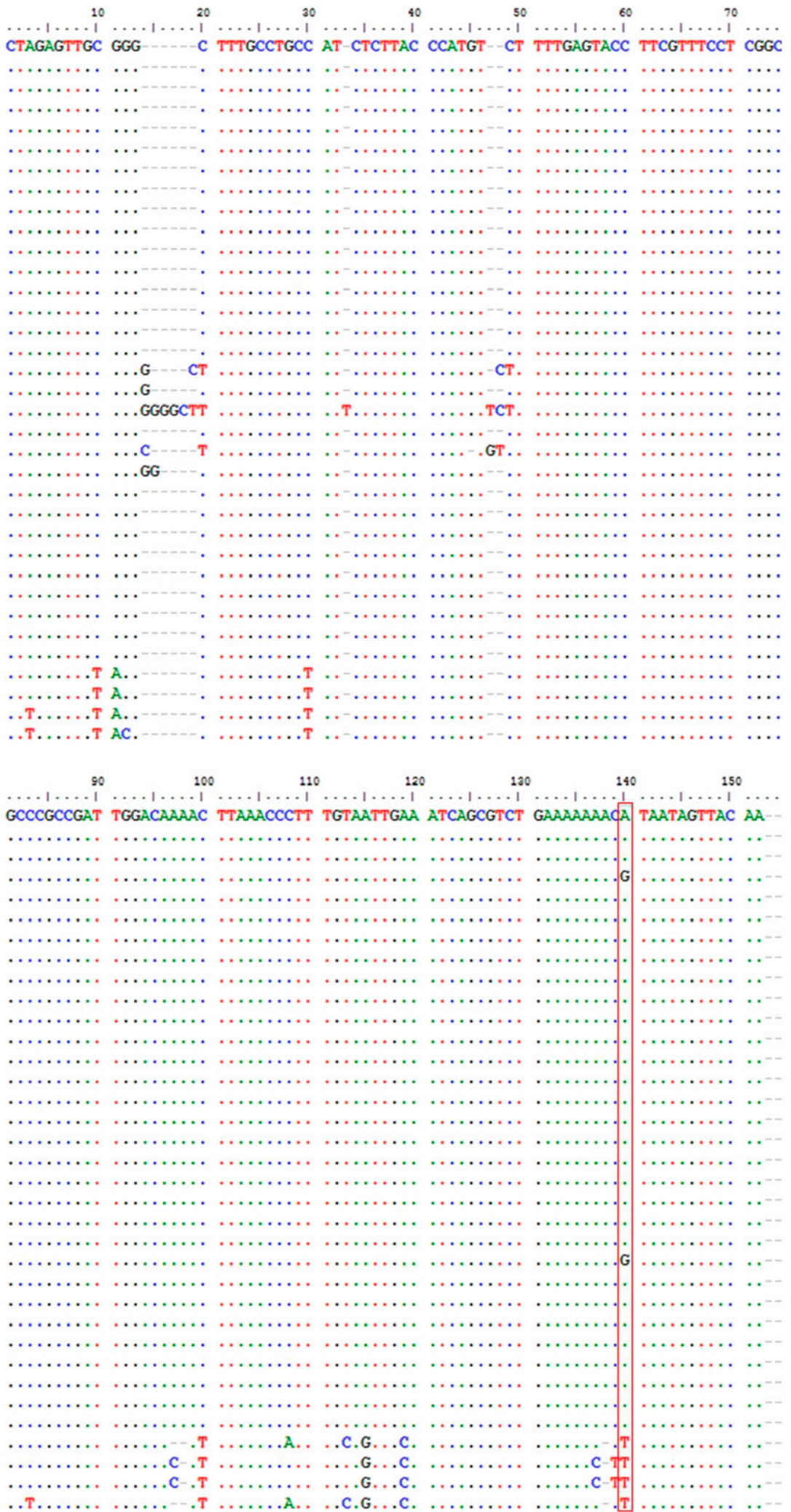

Fig. 1. Multiple sequence alignment of the internal transcribed spacer-1 region of ribosomal DNA of Didymella bryoniae isolates from Florida and Georgia, indicating the single nucleotide substitution at position 131 (alignment position 140). 
polymorphic across the 35 isolates were used for analysis. The presence or absence of a marker allele (band) was scored as 1 or 0 , respectively. Faint markers (bands) were not included in the analysis. The relative size of each band was determined by comparison with a 1-kb ladder (Promega Corps.). After processing the gel images for individual primers, composite data were constructed for the selected set of primers, and all pairwise similarity values were calculated using Jaccard's similarity coefficient (Sneath and Sokal 1973). Cluster analysis was performed using Jaccard's coefficient and a dendrogram was constructed using the unweighted pair-group method with the arithmetic average (UPGMA) clustering algorithm (Sneath and Sokal 1973).

\section{Results}

Morphology of the isolates. Based on colony morphology, growth rate, conidial size, and presence of septa (Keinath et al. 1995) on QPDA after 12 days, 31 isolates were determined to be $D$. bryoniae and the remaining 4 isolates (DB-27, DB-35, DB-43, and DB-45) to be other Phoma spp. (Table 1). Among the D. bryoniae isolates, 21 produced a medium-gray or dark-gray colony with white or olive aerial mycelium and gray to dark lower colony color, 6 isolates produced white colonies with black or a light-white color on the lower agar surface, and 4 isolates produced light-brown to olive-drab colonies with a black or dark-brown color on the lower agar surface (Table 4). All four of the other Phoma spp. isolates produced light-green or brown to silver colonies with a black or brown color on the lower agar surface. Among the $D$. bryoniae isolates, 25 produced pycnidia and pseudothecia in a relatively uniform distribution. The $D$. bryoniae isolates had growth ranging from 3.5 to $20.2 \mathrm{~mm}$ at the end of 12 days. Isolates of Phoma spp. had growth ranging from 5.4 to $7.5 \mathrm{~mm}$ over the same duration. Among the D. bryoniae isolates, the length and width of conidia varied, with septate conidia produced by a majority of the isolates $(n=18)$; no conidial septation was observed for the other Phoma spp. isolates. Cultural characteristics on MEA and V8 media were similar to that on QPDA but faster colony growth was observed on MEA for $77 \%$ of the isolates compared with growth on QPDA Supplementary Table S1). However, most isolates produced predominantly white colonies on MEYEA, with the exception of eight isolates (DB-11, DB-38, DB-39, DB-40, DB-42, DB-43, DB-44, and DB-45) (data not shown).

Pathogenicity assay. All of the D. bryoniae and Phoma spp. isolates, regardless of the host of origin, were pathogenic on Melody watermelon. The results were similar for both trials, with no significant trial interaction with isolates; and, hence, the datasets for the two trials were combined for analysis. The control plants did not develop any symptoms of gummy stem blight. The pathogen was reisolated from all of the inoculated plants onto QPDA, thus confirming Koch's postulates. The isolates had varying degrees of virulence (Table 1), with $40 \%$ of the isolates extremely virulent ( 75 to $100 \%$ disease severity), $26 \%$ highly virulent (50 to $75 \%$ disease severity), $14 \%$ moderately virulent ( 25 to $50 \%$ disease severity), and the remaining $20 \%$ with low levels of virulence ( 1 to $25 \%$ disease severity). Among the four isolates of other Phoma spp., one isolate was highly virulent (DB-27) and one (DB-43) was extremely virulent, while isolates DB-35 and DB-45 had low and moderate virulence, respectively. There was no clear association between isolate virulence on watermelon

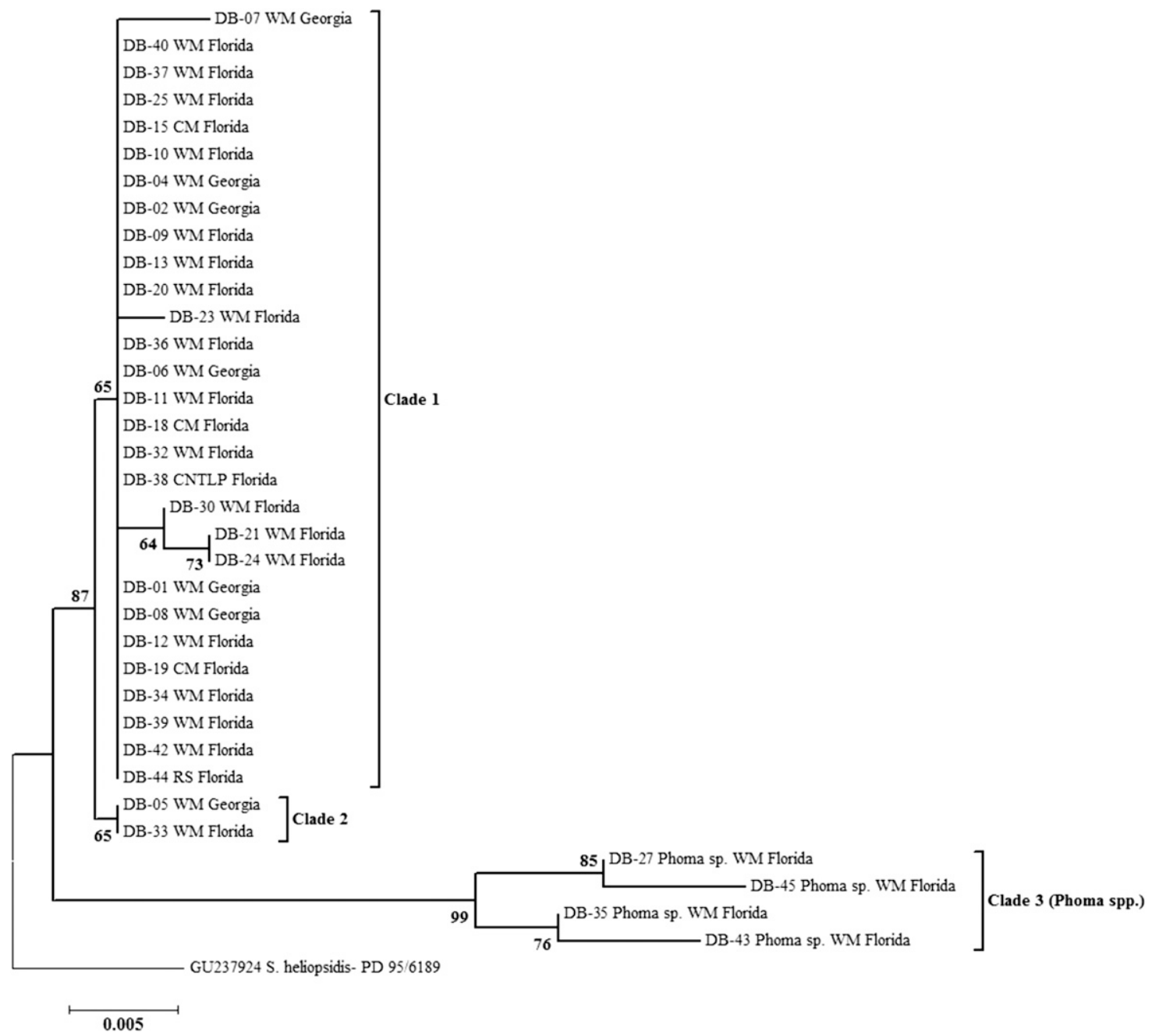

Fig. 2. Phylogenetic neighbor joining tree of the 545 -bp internal transcribed spacer region of ribosomal DNA of Didymella bryoniae isolates from Florida and Georgia, constructed using MEGA 5.2 software using 1,000 bootstrap replicates and Stagonosporopsis heliopsidis as the outgroup. 
and host of origin. For example, two Canary melon isolates from Florida (DB-15 and DB-18) were highly virulent on watermelon, whereas isolate DB-19 from Canary melon had low virulence on watermelon (Table 1).

Diversity analysis using RG-specific SCAR primers. PCR analysis of the 35 isolates using the RG-specific primers RG-I-F and RG-I-R resulted in amplification of a 735-bp fragment of DNA for 25 of the isolates (Table 1). Sequence analysis of the amplified fragments showed $99 \%$ identity with that of $S$. cucurbitacearum isolate GSB23 (accession number GQ872463) from the NCBI database, and the 25 isolates shared 96 to $99 \%$ sequence identity (data not shown). The RG-II primers did not amplify DNA of any of the isolates (Table 1). However, the Phoma-specific primers RG-III-F and RG-III-R produced an amplification product of $704 \mathrm{bp}$ for one of the watermelon isolates from Florida, DB-27 (Table 1). Analysis of the D. bryoniae isolates using the RG-specific primers showed that $71 \%$ belonged to the RG-I group, 1 isolate to the RG-III Phoma group (DB-27), and the remaining $26 \%$ of the isolates tested ( 9 of 35 ) did not amplify with any of the three sets of RG primers (Table 1).

Genetic diversity analysis using ITS primers. PCR analysis using ITS 1 and ITS4 primers produced an amplicon of $545 \mathrm{bp}$ for all 35 isolates (data not shown). Sequence analysis of the amplified product showed 98 to $99 \%$ identity with that of the D. bryoniae (S. cucurbitacearum) isolates in the NCBI database, except for four watermelon isolates from Florida (DB-27, DB-35, DB-43, and DB-45), which showed $99 \%$ sequence identity with that of other Phoma spp. in the NCBI database. Comparative analysis among the isolates showed that the four isolates of other Phoma spp. exhibited only 96 to $97 \%$ identity with that of the $D$. bryoniae isolates. In all, $33 \mathrm{D}$. bryoniae isolates had an adenine residue at position 131 of the ITS1 region (alignment position 140), whereas 2 watermelon isolates, one each from Georgia and Florida (DB-05 and DB-33, respectively), had a guanine substitution (Fig. 1). Sequence alignment of the amplified regions showed that the Phoma spp. contained nine substitutions and two deletions in the ITS1 region and three substitutions and two deletions in the ITS2 region compared with the $D$. bryoniae isolates. The ITS1 region among the $D$. bryoniae isolates was more variable than the ITS2 region, with an identity of 92 to $100 \%$ (data not shown). A watermelon isolate from Florida, DB-24, was highly variable due to three insertions and two substitutions, with an identity of 92 to $94 \%$; and similarly for DB-21 from Florida, with 96 to $97 \%$ sequence identity (Fig. 1). However, the ITS1 region of the four other Phoma spp. showed only 84 to $91 \%$ identity with that of the D. bryoniae isolates, clearly demarcating the two groups of isolates. There was considerable variability in the ITS1 region of the four Phoma spp. isolates. DB-27 shared 98\% sequence identity with that of DB-45 but only $96 \%$ identity with that of DB-35 and DB-43 (Fig. 1). Phoma isolates DB-35 and DB-43 shared $99 \%$ sequence identity. The ITS2 region of these isolates was highly conserved, with an identity of 99 to $100 \%$, with the exception of two Phoma spp. isolates, DB-27 and DB-45, which exhibited 96 to $97 \%$ identity with the ITS2 sequences of the other isolates and 99\% identity between these two isolates (data not shown).

Phylogenetic analysis. Phylogenetic analysis of the ITS rDNA of the 35 D. bryoniae and other Phoma spp. isolates clustered the isolates into three groups with a bootstrap consistency of $87 \%$ (Fig. $2)$. The majority of isolates $(n=29)$ clustered in clade 1 . Among these isolates in clade 1, 3 watermelon isolates from Florida (DB-30, DB21 and DB-24) exhibited slight variation compared with the other 26 isolates and formed a subgroup within clade 1 . Clade 2 comprised two watermelon isolates, DB-05 from Georgia and DB-33 from Florida. The ITS region clearly demarcated the four isolates of other Phoma spp., which constituted clade 3 (Fig. 2).

To assess genetic diversity further, phylogenetic analysis of the ITS region of the isolates was performed along with available ITS sequences of $D$. bryoniae and Phoma spp. in the NCBI database, which clustered the isolates into three clades (Fig. 3). The four Phoma spp. isolates from this study again were grouped in a clade separate from the $D$. bryoniae isolates. The majority of the isolates in clade $1(n=29)$ were clustered as subgroup 1a, with the exception of isolates DB-09, DB-13, DB-20, DB-36, DB-40, and DB-44, which formed subgroup $1 \mathrm{~b}$ within clade 1. Subgroup 1a consisted of a majority of the isolates from Florida and Georgia, which tested positive with the RG-I-specific primers (Table 1), with the exception of DB-06, which did not react with any of the SCAR primers. This subgroup also included isolates from hosts other than watermelon (e.g., muskmelon and Canary melon). Subgroup $1 \mathrm{~b}$ comprised eight watermelon isolates from Florida (including DB-21, DB-24, and DB23) and one isolate from squash. Moreover, isolates DB-21, DB-24, and DB-23 formed a different subgroup within subgroup 1b. Among the isolates in subgroup 1b, five isolates (DB-13, DB-20, DB-21, DB-23, and DB-24) tested positive with the RG-1-specific primers

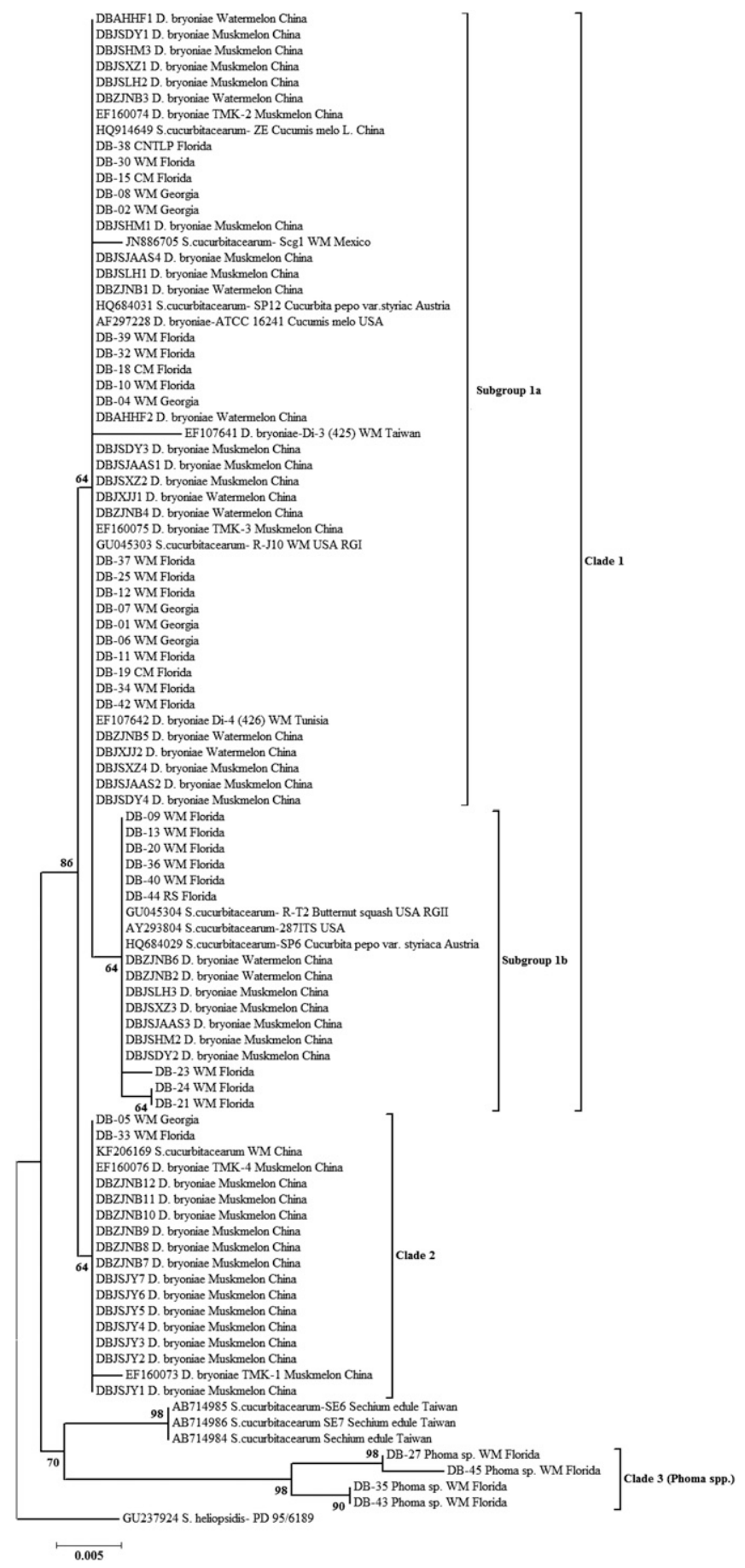

Fig. 3. Phylogenetic neighbor joining tree of internal transcribed spacer region of ribosomal DNA of Didymella bryoniae isolates from Florida and Georgia with that of available isolates in the GenBank National Center for Biotechnology Information database, constructed using MEGA 5.2 software using 1,000 bootstrap replicates and Stagonosporopsis heliopsidis as the outgroup. 
but not isolates DB-09, DB-36, DB-40, and DB-44. Clade 2 consisted of two watermelon isolates, one from Georgia and one from Florida (DB-05 and DB-33, respectively). DB-05 amplified with the RG-I primers, whereas DB-33 did not (Table 1). Clade 2 isolates clustered with high identity ( $64 \%$ bootstrap value) with some of the $D$. bryoniae isolates from muskmelon along with one watermelon isolate from China (Fig. 3).

PCR-RFLP analysis. Restriction analysis of the PCR-amplified 545-bp ITS region of rDNA using the enzymes $M s p$ I and TaqI produced identical restriction patterns for 34 of the 35 isolates, with the exception being DB-01, which produced a slightly different restriction pattern (data not shown).

Diversity analysis using RAPD. Among the 15 RAPD primers evaluated, 13 failed to amplify DNA from one or more isolates. Primers OPAA-04 and OPAA-15 were selected to estimate pairwise genetic similarity among the isolates. On average, these primers produced 20 to 25 polymorphic and reproducible markers (Fig. 4). On the basis of genetic similarity and UPGMA cluster analysis, the isolates were grouped into two discrete clusters with a majority (28 isolates) in RAPD group 1, regardless of their origin from Florida or Georgia or host of origin (Fig. 5). RAPD group 2 included isolates of the other Phoma spp., with 60\% identity (bootstrap consistency of 94\%). However, three isolates (DB-06, DB-33, and DB-01) shared $<50 \%$ identity with RAPD groups 1 and 2 and did not cluster with either group (Fig. 5). RAPD phylogenetic analysis of the whole genome indicated that isolate DB-06 (a watermelon isolate from Georgia) was the most distinct followed by DB-33 (a watermelon isolate from Florida) and DB-01 (a watermelon isolate from Georgia). However, the isolates in group 1 exhibited greater variability within the group. The isolates in group 1 were further subclustered into group 1a, which contained only Florida isolates from both watermelon and canary melon; subgroup $1 \mathrm{~b}$, which consisted of Georgia and Florida isolates from watermelon only; and subgroup 1c, which included DB-02, DB-38, DB-09, DB-32, DB-36, DB-11, DB-37, and DB-44, which shared 55 to $72 \%$ identity with the other subgroup isolates. The most distant of the isolates was DB-44, a squash isolate from Florida (Fig. 5).

\section{Discussion}

Morphological characterization of the isolates of D. bryoniae and other Phoma spp. from watermelon and other cucurbit crops in Florida and Georgia demonstrated variation among the isolates. Similar morphological variation among $D$. bryoniae isolates as well as between D. bryoniae and isolates of other Phoma spp. was reported by Keinath et al. (1995). The variation in conidial characteristics observed in this study concurred with variation previously reported, including size of conidia and the percentage of monoseptate conidia in D. bryoniae isolates (Choi et al. 2010; Keinath et al. 1995).

In this study, the pathogenicity assays of isolates of D. bryoniae on plants of Melody watermelon revealed that the isolates varied in virulence. The isolates collected from the same host (watermelon) also exhibited differences in virulence. The majority of watermelon isolates $(n=20)$ were highly or extremely virulent on watermelon seedlings. However, 10 watermelon isolates exhibited low or moderate virulence. Similar observations were made by Shim et al. (2006) and St. Amand and Wehner (1995). Among the D. bryoniae isolates from hosts other than watermelon, two Canary melon isolates (DB-15 and DB-18) and the muskmelon isolate (DB-38) were highly virulent on watermelon, whereas another Canary melon isolate (DB19) and a squash isolate (DB-44) had low virulence on watermelon. However, pathogenicity tests of these isolates were only performed on watermelon seedlings, and further studies need to be conducted on additional cucurbits such as muskmelon, Canary melon, and squash to study host preference of the isolates more thoroughly. Information on the relative susceptibility of watermelon and other cucurbits to isolates from different hosts of origin can be useful for resistance breeding programs. Other than host and geographic origin, this study did not demonstrate any association between isolate

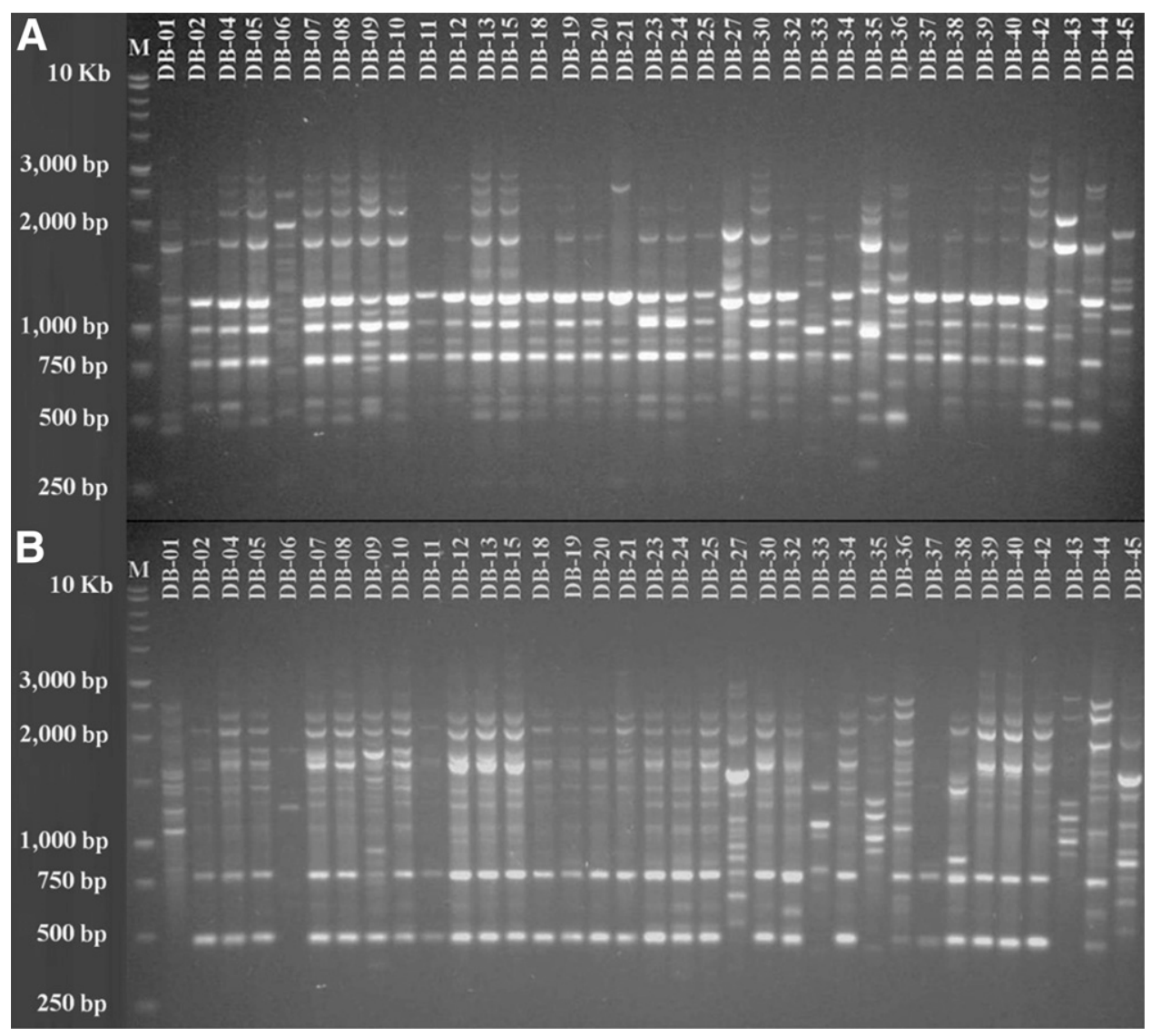

Fig. 4. Random amplified polymorphic DNA analysis of Didymella bryoniae isolates from Florida and Georgia using operon primers $A, O P A A-04$ and $B, O P A A-15 . M=1-k b$ marker. 
virulence and RG grouping pattern. Most of the RG-I positive isolates varied in virulence on watermelon while the RG-I negative isolates had low virulence, with the exception of two isolates (DB-06 and DB-23), which contradicted results of previous reports (Keinath et al. 1995; Shim et al. 2006; Somai et al. 2002a; Zuniga 1999). Even though isolates in RG-III or the other Phoma spp. group were reported to have low virulence (Keinath et al. 1995; Somai et al. 2002a), this study indicated that some isolates of the other Phoma spp. (specifically, DB-33 and DB-45) were low and moderately virulent, while isolates DB-27 and DB-43 were highly virulent. This may indicate additional potential groups (variation) within the other Phoma spp. collected from Florida, as previously reported by Jenkins and Person (1973). However, the long period that plants were observed after inoculation (30 days) in this study compared with other studies (Keinath et al. 1995; Somai et al. 2002a) could also be the reason for observing more virulence of the two other Phoma spp. isolates used in this study.

Analysis of the D. bryoniae isolates from Florida and Georgia using RG-specific SCAR primers showed that the majority (71\%) belonged to RG-I. This agrees with earlier reports of RG-I predominant groups in the United States (Keinath et al. 2001; Kothera et al. 2003). The remaining isolates did not amplify with the RGspecific primers. This may be due to nonspecificity of the primers or perhaps that the RG-specific SCAR primers are not effective for differentiating the grouping patterns among isolates prevalent in Florida and Georgia. Among the four isolates of other Phoma spp. studied, only DB-27 amplified with the RG-III specific primers. Analysis of the ITS region of the isolates indicated that the ITS1 region could be used to differentiate variability among $D$. bryoniae isolates as well as the Phoma spp., whereas the ITS2 region only produced a clear demarcation between the isolates of $D$. bryoniae versus those of the other Phoma spp. These results confirm previous reports of rapid evolution and greater variability of the ITS1 versus ITS2 region in fungal communities (Hershkovitz and Lewis 1996; Hillis and Dixon 1991; Nilsson et al. 2008).

Among the clades detected by phylogenetic analysis of the 35 D. bryoniae isolates, clade 1 comprised both RG-I-positive and -negative isolates. Hence, it was not possible to group the isolates according to RG classification. Moreover, the isolates in clade 2 also differed in that DB-05 tested positive with the RG-I-specific primers while DB-33 was negative. Phylogenetic analysis of these Florida and Georgia isolates in comparison with isolate sequences from the NCBI database demonstrated a wide diversity among the $D$. bryoniae isolates. Phylogenetic analysis separated the $D$. bryoniae isolates from isolates of the other Phoma spp., and the latter were distantly related to a $S$. cucurbitacearum isolate from chayote melon in Taiwan. Inclusion of the additional sequences from the NCBI database resulted in a subgrouping of clade 1 isolates into subgroups $1 \mathrm{a}$ and $1 \mathrm{~b}$.

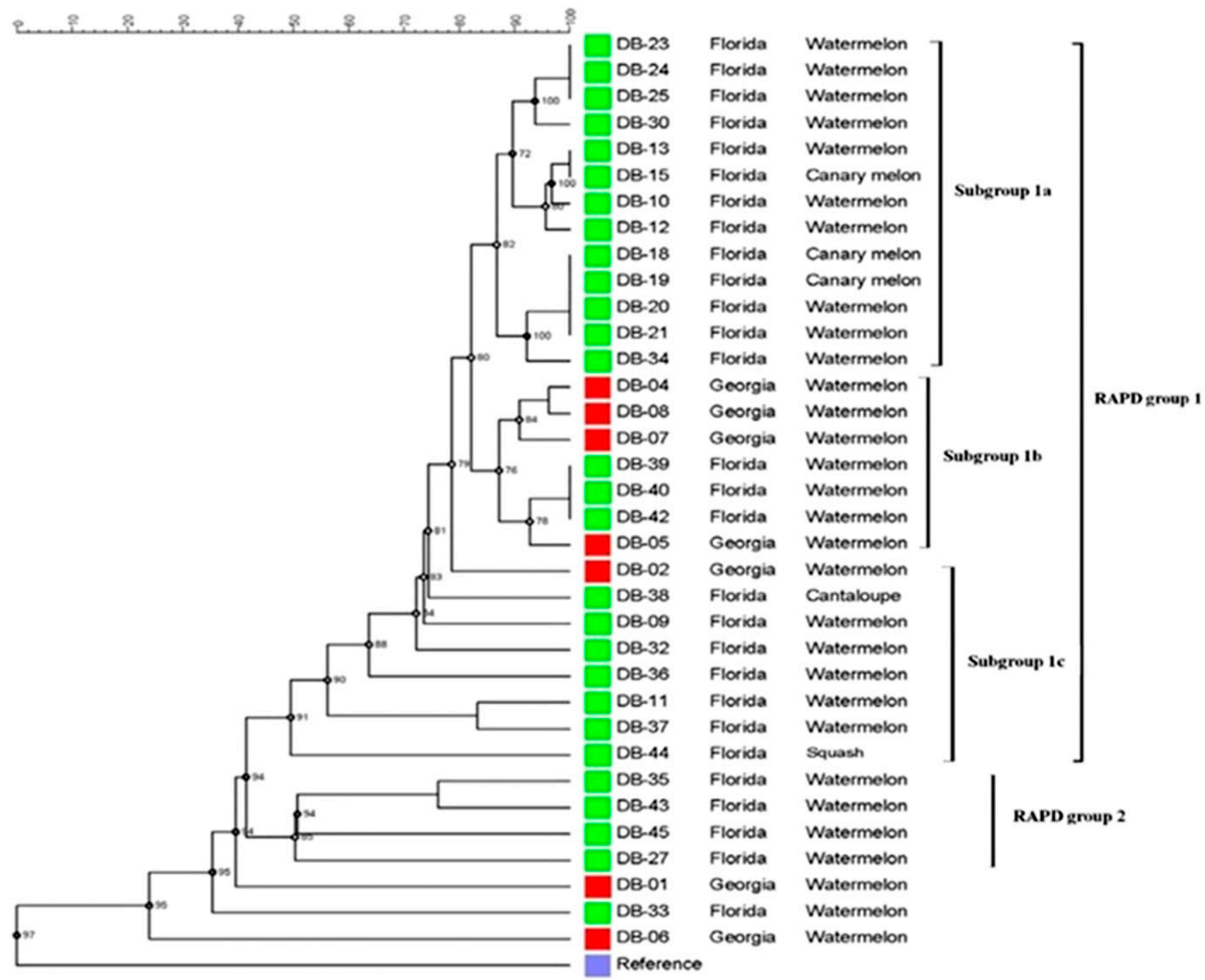

Fig. 5. Phylogenetic unweighted pair-group method analysis tree of Didymella bryoniae isolates from Florida and Georgia based on random amplified polymorphic DNA (RAPD) analysis, constructed using GelCompar II software. Analysis was performed with reference to the 1-kb marker. Each red bar indicates an isolate from Georgia, while each green bar represents an isolate from Florida. Reference indicates a 1-kb marker. 
Clustering of the two reference isolates from the NCBI database, S. cucurbitacearum isolate R-J10 (GU045303, reported to be an RG-I group) and S. cucurbitacearum isolate R-T2 (GU045304, reported to be an RG-II group), with subgroups $1 \mathrm{a}$ and $1 \mathrm{~b}$, respectively, indicated that subgroup 1a included the RG-I group while subgroup $1 \mathrm{~b}$ may comprise primarily the RG-II group, even though none of the isolates in this latter subgroup reacted with the RG-II-specific primers. This needs further analysis because a negative association exists between the grouping detected in this study and previous RG-SCAR primer groupings (Keinath et al. 2001; Somai et al. 2002b). Subgroups 1a (RG-I group) and 1b (RG-II group) exhibited a close relationship (98 to $99 \%$ ), which corroborates the earlier report of Somai et al. (2002a).

The phylogenetic analysis indicated a greater sequence identity of two watermelon isolates, DB-05 and DB-33, with 15 D. bryoniae isolates from muskmelon and 1 watermelon isolate from China, which constituted clade 2. Similar to DB-05 and DB-33, all the isolates in clade 2 had a single nucleotide substitution of $\mathrm{A} / \mathrm{G}$ at position 131 of the ITS1 region. Earlier reports showed that RG-I isolates had an adenine or guanine residue at this location, and RG-II and RG-IV isolates had an adenine residue (Somai et al. 2002a). This study showed no association between RG groups and the single-nucleotide polymorphism. Even though RG-I isolates had an adenine or guanine residue, two D. bryoniae isolates (DB-05 and DB-33) with guanine substitutions could not be classified in RG-I based on distant phylogenetic clustering as well as a differential response to the RG-I specific primers. Isolates DB-05 and DB-33 could not be considered as belonging to RG-II or RG-IV based on the single nucleotide substitution, as previously reported. This suggests that these two isolates may be unique to Florida and Georgia.

Large quantities of cucurbit seed are imported into the United States each year (United States Department of Agriculture 2013a, b). The global nature of seed production and international seed trade significantly increases the risk of introducing seedborne pathogens into regions where seed is imported (Walcott 2008). The close genetic relationship of watermelon isolates DB-05 and DB-33 with the muskmelon isolates and a watermelon isolate from China could provide insights into movement of the pathogen across geographic regions on seed. Even though the major source of inoculum in cucurbit fields is inoculum surviving on cucurbit debris and subsequent dispersal of spores (Keinath 2002), seedling infections in greenhouses have been traced to contaminated seed (Brown et al. 1970; Lee et al. 1984). Large-scale greenhouse transplant production environments are highly conducive to gummy stem blight development that can begin from a very low incidence of contaminated seed because of the density of transplant production and use of overhead irrigation (Keinath 1996; Koike 1997). Moreover, the host range of the pathogen means potential introduction of the fungus on infected seed lots of other cucurbits, including muskmelon and squash. In addition to watermelon, China is also the largest supplier of muskmelon seed to the United States, and other major suppliers include Thailand, France, and Guatemala (United States Department of Agriculture 2013b). The total seed supplies from these countries accounted for $33,158 \mathrm{~kg}$ in 2011 , which was $93.5 \%$ of the total U.S. muskmelon seed imported that year (United States Department of Agriculture 2013b). Because of this risk of introducing isolates into the United States on imported seed, extensive genetic fingerprinting is required to understand the genetic nature of $D$. bryoniae isolates currently present in different regions of the United States, and by comparing these with isolates in other countries or isolates detected directly on seed lots imported into the United States.

The RAPD markers evaluated in this study did not give much information on the diversity of isolates assessed in this study but clearly differentiated isolates of the other Phoma spp. from the D. bryoniae isolates. There was no clear relationship between results of the ITS analysis and the RAPD analysis, which may be due to the fact that the ITS analysis is based on a conserved portion of the genome, while RAPD analysis is based on multiple loci across the entire genome (Welsh and McClelland 1990; Williams et al. 1990). Even though the entire fungal genome is subjected to faster evolution than single ITS loci (Bruns et al. 1991), the RAPD analysis in this study produced inadequate information. This could be due to the homothallic nature of the $D$. bryoniae isolates resulting in fewer variations across the entire genome than single loci. Advanced genetic fingerprinting techniques such as microsatellite marker analysis of the isolates is in progress to gain a better understanding of the genetic diversity of these isolates.

In conclusion, ITS analysis provided a greater understanding than RAPD fingerprinting of the genetic diversity of the $D$. bryoniae isolates from Florida and Georgia evaluated in this study. The genetic similarity of the two D. bryoniae isolates (DB-05 and DB-33) to that of international isolates indicates the importance of understanding the movement of pathogen through seed or transplants. The potential entry of new isolates of the pathogen into the United States on imported cucurbit seed lots could pose a risk to U.S. cucurbit production. The finding from this study that the two other Phoma spp. (DB-27 and DB-45) were highly virulent on watermelon indicates potential variations among the isolates other than previously described. These findings validate the need for routine characterization of D. bryoniae and other Phoma spp. isolates from cucurbits in order to understand the occurrence of unique and highly virulent isolates that could be adverse to cucurbit production in the United States.

\section{Acknowledgments}

This project is funded through the University of Florida IFAS Dean's Start-Up Fund and the National Natural Science Foundation of China (31301794) funds We thank S. Miller, Department of Biological Science, Florida State University for providing access to DNA sequencing facilities; T. Keinath at Clemson University and E. Goss at the University of Florida for reviewing the article; M. Brewer at the University of Georgia for research consultations; R. Trawick, D. Mullins, M. Orwatt, and B. Hochmuth of the University of Florida and D. Langston of the University of Georgia for helping with sample collection; and L. Ritchie, H. Dankers, and K. Beckham at the University of Florida for their help in setting up experiments for this study.

\section{Literature Cited}

Atlas, R. M. 2010. Handbook of Microbiological Media, 4th ed. CRC Press, Boca Raton, FL.

Aveskamp, M. M., de Gruyter, J., Woudenberg, J. H. C., Verkley, G. J. M., and Crous, P. W. 2010. Highlights of the Didymellaceae: A polyphasic approach to characterise Phoma and related pleosporalean genera. Stud. Mycol. 65:1-60.

Bala, G., and Hosein, F. 1986. Studies on gummy stem blight disease of cucurbits in Trinidad. Trop. Agric. 63:195-197.

Brown, M. E., Howard, E. M., and Knight, B. C. 1970. Seed-borne Mycosphaerella melonis on cucumber. Plant Pathol. 19:198.

Bruns, T. D., White, T. J., and Taylor, J. W. 1991. Fungal molecular systematics. Annu. Rev. Ecol. Syst. 22:525-564.

Choi, I. Y., Choi, J. N., Choi, D. C., Sharma, P. K., and Lee, W. H. 2010. Identification and characterization of the causal organism of gummy stem blight in the muskmelon (Cucumis melo L.). Mycobiology 38:166-170.

Hall, T. A. 1999. Bioedit: A user-friendly biological sequence alignment editor and analysis program for windows 95/98/NT. Nucleic Acids Symp. Ser. 41:95-98.

Hershkovitz, M. A., and Lewis, L. A. 1996. Deep-level diagnostic value of the rDNA-ITS region. Mol. Biol. Evol. 13:1276-1295.

Hillis, D. M., and Dixon, M. T. 1991. Ribosomal DNA: Molecular evolution and phylogenetic inference. Q. Rev. Biol. 66:411-453.

Horsfall, J. G., and Barratt, R. W. 1945. An improved system for measuring plant diseases. (Abstr.) Phytopathology 35:655.

Jenkins, S. F., Jr., and Person, L. H. 1973. Ascochyta blight of cucurbits caused by Ascochyta phaseolorum. (Abstr.) Phytopathology 63:444.

Keinath, A. P. 1996. Spread of Didymella bryoniae from contaminated watermelon seed and transplants in greenhouse and field environments. Pages 65-72 in: Recent Research Developments in Plant Pathology, Vol. 1. S. G. Pandalai, ed. Research Signpost, Trivandrum, India.

Keinath, A. P. 2002. Survival of Didymella bryoniae in buried watermelon vines in South Carolina. Plant Dis. 86:32-38

Keinath, A. P., and Duthie, I. A. 1998. Yield and quality reductions in watermelon due to anthracnose, gummy stem blight and black rot. Pages 77-90 in: Recent Research Developments in Plant Pathology, Vol. 2. S. G. Pandalai, ed. Research Signpost, Trivandrum, India

Keinath, A. P., Farnham, M. W., and Zitter, T. A. 1995. Morphological, pathological and genetic differentiation of Didymella bryoniae and Phoma spp. isolated from cucurbits. Phytopathology 85:364-369.

Keinath, A. P., Somai, B. M., and Dean, R. A. 2001. Method of diagnosing gummy stem blight in plants using a polymerase chain reaction assay. U.S. Patent $6,258,537 \mathrm{~B} 1$.

Koike, S. T. 1997. First report of gummy stem blight, caused by Didymella bryoniae, on watermelon transplants in California. Plant Dis. 81:1331.

Kothera, R. T., Keinath, A. P., Dean, R. A., and Farnham, M. W. 2003. AFLP analysis of a worldwide collection of Didymella bryoniae. Mycol. Res. 107: 297-304. 
Lee, D. H., Mathur, S. B., and Neergard, P. 1984. Detection and location of seedborne inoculum of Didymella bryoniae and its transmission in seedlings of cucumber and pumpkin. Phytopathol. Z. 109:301-308.

McGrath, D. J., Vawdrey, L., and Walker, I. O. 1993. Resistance to gummy stem blight in muskmelon. HortScience 28:930-931.

Nilsson, R. H., Kristiansson, E., Ryberg, M., Hallenberg, N., and Larsson, K.-H. 2008. Intraspecific ITS variability in the Kingdom Fungi as expressed in the international sequence databases and it's implications for molecular species identification. Evol. Bioinf. Online 4:193-201.

Norton, J. D., and Cosper, R. D. 1989. AC-70-154, a gummy stem blight resistant muskmelon breeding line. HortScience 24:709-711.

Norton, J. D., Cosper, R. D., Smith, D. A., and Rymal, K. S. 1986. AU-Jubilant and AU-Producer watermelons. HortScience 21:1460-1461.

Punithalingam, E., and Holliday, P. 1972. Didymella bryoniae. No. 332 in: Descriptions of Pathogenic Fungi and Bacteria. Commonwealth Mycological Institute, Kew, England.

Santos, G. R. D., Ferreira, M. A. D. S. V. I., Pessoa-Filho, M. A. C. P., Ferreira, M. E., and Cafe'-Filho, A. C. 2009. Host specificity and genetic diversity of Didymella bryoniae from cucurbitaceae in Brazil. J. Phytopathol. 157: 265-273.

Schoch, C. L., Seifert, K., and Huhndorf, S. 2012. Nuclear ribosomal internal transcribed spacer (ITS) region as a universal DNA barcode marker for fungi. Proc. Natl. Acad. Sci. USA 109:6241-6246.

Shim, C. K., Seo, K., Hyeong Jin Jee, H. J., and Kim, H. K. 2006. Genetic diversity of Didymella bryoniae for RAPD profiles substantiated by SCAR marker in Korea. Plant Pathol. 22:36-45.

Sitterly, W. R., and Keinath, A. P. 1996. Gummy stem blight. Pages 27-28 in: Compendium of Cucurbit Diseases. T. A. Zitter, D. L. Hopkins, and C. E. Thomas, eds. American Phytopathological Society, St. Paul, MN.

Sneath, P., and Sokal, R. 1973. Numerical Taxonomy: The Principles and Practice of Numerical Classification. W. H. Freeman, San Francisco.

Somai, B. M., Dean, R. A., Farnham, M. W., Zitter, T. A., and Keinath, A. P. 2002a. Internal transcribed spacer regions 1 and 2 and random amplified polymorphic DNA analysis of Didymella bryoniae and related Phoma species isolated from cucurbits. Phytopathology 92:997-1004.

Somai, B. M., Keinath, A. P., and Dean, R. A. 2002b. Development of PCRELISA for detection and differentiation of Didymella bryoniae from related Phoma species. Plant Dis. 86:710-716.

St. Amand, P. C., and Wehner, T. C. 1991. Crop losses to 14 diseases of cucumber in North Carolina from 1983 to 1988. Cucurb. Genet. Crop. 14:15-17.
St. Amand, P. C., and Wehner, T. C. 1995. Eight isolates of Didymella bryoniae from geographically diverse areas exhibit variation in virulence but no isolate by cultivar interaction on Cucumis sativus. Plant Dis. 79:1136-1139.

Tajima, F., and Nei, M. 1984. Estimation of evolutionary distance between nucleotide sequences. Mol. Biol. Evol. 1:269-285.

Tamura, K., Peterson, D., Peterson, N., Stecher, G., Nei, M., and Kumar, S. 2011. MEGA5: Molecular evolutionary genetics analysis using maximum likelihood, evolutionary distance, and maximum parsimony Methods. Mol. Biol. Evol. 28 2731-2739.

Thompson, J. D., Higgine, D. G., and Gibson, T. J. 1994. CLUSTAL W Improving the sensitivity of multiple sequence alignment through sequence weighting, position specific gap penalties and weight matrix choice. Nucleic Acids Res. 22:4673-4680.

United States Department of Agriculture National Agricultural Statistics Service. 2013. Vegetables-2012. Online publication, http://usda.mannlib.cornell edu/usda/nass/VegeSumm//2010s/2013/VegeSumm-01-29-2013.pdf.

United States Department of Agriculture. 2013a. Foreign Agricultural Trade of the United States FATUS. U.S. Watermelon Industry (89029). Online publication. http://usda.mannlib.cornell.edu/MannUsda/viewDocumentInfo.do? documentID $=1399$

United States Department of Agriculture. 2013b. Foreign Agricultural Trade of the United States FATUS. U.S. Cantaloup Statistics (02002). Online publication. http://usda.mannlib.cornell.edu/MannUsda/viewDocumentInfo.do? documentID $=1478$

Walcott, R. R. 2008. Integrated pest management of bacterial fruit blotch of cucurbits. Pages 191-209 in: Integrated Management of Diseases Caused by Fungi, Phytoplasma and Bacteria. A. Ciancio and K. G. Mukerji, eds. Springer, Dordrecht, The Netherlands.

Welsh, J., and McClelland, M. 1990. Fingerprinting genomes using PCR with arbitrary primers. Nucleic Acids Res. 18:7213-7218.

White, T. J., Bruns, T., Lee, S., and Taylor, J. 1990. Amplification and direct sequencing of fungal ribosomal RNA genes for phylogenetics. Pages 315-322 in: PCR Protocols: A Guide to Methods and Applications. M. A. Innis, D. H. Gelfand, J. J. Sninsky, and T. J. White, eds. Academic Press, San Diego, CA.

Williams, J. G. K., Kubelik, A. R., Livak, K. J., Rafalski, J. A., and Tingey, S. V. 1990. DNA polymorphisms amplified by arbitrary primers are useful as genetic markers. Nucleic Acids Res. 18:6531-6535.

Zuniga, T. L. 1999. Gummy stem blight (Didymella bryoniae) of cucurbits: Pathogen characterization and inheritance of resistance in melon (Cucumis melo). Ph.D. dissertation, Cornell University, Ithaca, NY. 